\title{
LIFELONG LEARNING AND EDUCATIONAL CHALLENGES IN COVID 19 PANDEMIC
}

\author{
Elena Rizova ${ }^{38}$ \\ University Ss Cyril and Methodius, Faculty of philosophy, Skopje
}

\begin{abstract}
Learning as condition humana is a precondition for human survival and development, which implies that lifelong learning represents an evolutionary product of human society and culture. As a concept, lifelong learning has always been adaptable to the social, political, educational and ideological interests of certain societies, organizations, cultures and traditions. In times of world pandemic caused by a deadly virus named Covid 19, education and learning are the one of the most powerful "fighting weapons" against the problem. Human kind is relying on the knowledge and skills of the scientist to find the solution for the problem that has put the whole world in hibernation. On the other hand, the pandemic has emphasized the differences in learning and education opportunities for children and adults for participating in electronic modes of education (e-learning). Despite the differences of technical and financial nature, there are some substantial differences among students which are competencies for self-learning and self-education that are in the main core of the concept of lifelong learning. These differences are leading reasons for students' educational and learning success, as well as for their personal fulfilment.

The purpose of this research paper is to present the possession of the learning to learn competence among university undergraduate students in the framework of the lifelong learning concept, which are crucial for educational success as well as continuous learning and education throughout peoples' lives. Results of the research will imply the correlation between the success of the studies and possession of several components of learning to learn competence.
\end{abstract}

Key words: lifelong learning, learning to learn, educational challenges.

\section{Lifelong learning and its implications in contemporary and challenging world}

Lifelong learning has been gaining a lot of significance in the transnational arena of global policy, especially in today's modern society characterized with fast changes and uncertainty in every societal area. Transnational policies set by world

${ }^{38}$ Contact address: elenarizova@fzf.ukim.edu.mk 
and European organizations are influencing the modification of educational concepts, systems and acknowledgments of learning and education, mainly in interrelation with wider ideologies.

It is undoubtedly that the interest and significance of lifelong learning is corresponding with the rapid development of science and technology as well as with societal changes that modern people are facing on an everyday basis. All these challenges presuppose those individuals should continuously obtain new knowledge and skills, adapt to the changing world, redefine strategies of education and learning, adapting to the new criteria and demands of the labor market, etc.

Hence, mutual elements and definitions about the concept of lifelong learning can be synthesized in several main tasks and/or goals that gravitate around lifelong learning essence.

1. Better future;

2. Focus on the process of learning;

3. Self-regulated organization of the learning process as an essential methodological postulate;

4. Changing role of the teacher;

5. Improving learning possibilities;

6. Mutual interconnection of all stakeholders included in the process of learning.

\section{Changing educational paradigm - from education to learning}

Twenty first century changes in all aspects of human life, work and development have been accenting the urgent need for continuing learning and education in order to stay up-to date with the new challenges of the societies. That presupposes those educational systems as well should be built upon a new model of learning - learning to learn or self-directed learning.

Actualization of self-regulated learning can be considered as a reaction to the changes in the post-industrialized societies. Actually, it represents an attempt to answer the political and societal question: Does the youth possesses knowledge, skills and attitudes for healthy and productive life in contemporary societies?

Learning to learn, or self-regulated learning are per se the answer to this question, because they are crucial aspects of the personal, educational, professional and societal autonomy of individuals. Unfortunately, in contemporary social constellations the presence of "encyclopedic knowledge" is still a matter of discussion in some country's vis á vis the affirmed necessity of students at all educational levels to obtain competences about self-directed or self-regulated learning, i.e., to be able to learn how to learn.

Lack of educational programs that include elements of self-regulated learning, insufficiency of hand-books and manuals for teachers to stimulate this kind of competences among students, as well as non-sufficient professional competences 
among educational staff for applying of innovative teaching methods, techniques and strategies - are still unbearable obstacle in educational systems in most countries, including Republic of Macedonia.

Self-regulated learning or competence "learning how to learn" should be a part of every contemporary concepted educational system that will provide students at all age groups (children, youngsters and adults) to be managers of their own learning and educational paths and to cope with the fast changes in knowledge-based societies. (Rizova, 2021)

\section{Key competences of lifelong learning}

Educational systems in today's knowledge-based societies have one specific educational or learning goal: to secure possibilities for students to obtain basic skills which will guarantee solid base for further personal and professional development and provide conditions for individuals to live and work together and have a happy and fulfilled lives.

The term competence is much more than just combination of knowledge, skills and attitudes. It presupposes the ability to confront the complex challenges of different situations in the much demanding societies.

In 1997, the Organization for Economic and Cultural Development (OECD) has launched the project (DeSeCo - Definition and selection of key competences) which has been aiming to secure solid data base for the possession of competences among youngsters and adults. Based on the gathered data, this project identified universal challenges of global economy and culture and build one NACRT selection of the most important "key competences".

Many international studies and experts' opinions agree that "competencies" represent combination of knowledge, skills and attitudes which are a base for personal development and fulfillment, active citizenship and inclusion as well for employability. Hence, we will give a short description about the main components of the competences:

- Knowledge is composed of the concepts, facts and figures, ideas and theories which are already established, and support the understanding of a certain area or subject.

- Skills are defined as the ability to carry out processes and use the existing knowledge to achieve results.

- Attitudes describe the disposition and mindset to act or react to ideas, persons or situations.

The Council of the European Union adopted a Recommendation on key competences for lifelong learning in 2006, which was renewed in May 2018. The new Recommendation identifies eight key competences essential to citizens for personal fulfilment, a healthy and sustainable lifestyle, employability, active citizenship and social inclusion. The reference framework presents successful ways to promote competence development through innovative learning approaches, assessment methods or support to educational staff so that all learners 
should achieve their full potential. To fulfil their different needs, the Recommendation encourages Member States to: provide quality early childhood education and care, improve school education and ensure excellent teaching, further develop initial and continuing vocational education and training, and modernize higher and adult education.

The key competences are developed throughout life, through formal, non-formal and informal learning in different environments, including family, school, workplace, neighborhood and other communities. All key competences are considered equally important and aspects essential to one domain will support competence development in another. For example, skills such as critical thinking, problem solving, team work, communication, creativity, negotiation, analytical and intercultural skills are embedded throughout the key competences. (European Commission, 2019)

These are the eight key competences:

1. Literacy competence

2. Multilingual competence

3. Mathematical competence and competence in science, technology and engineering

4. Digital competence

5. Personal, social and learning to learn competence

6. Citizenship competence

7. Entrepreneurship competence

8. Cultural awareness and expression competence

\section{Definition of personal, social and learning to learn competence}

Personal, social and learning to learn competence is the competence which is the starting point of this research. It is defined as the ability to reflect upon oneself, effectively manage time and information, work with others in a constructive way, remain resilient and manage one's own learning and career. It includes the ability to cope with uncertainty and complexity, learn to learn, support one's physical and emotional well-being, to maintain physical and mental health, and to be able to lead a health-conscious, future-oriented life, empathize and manage conflict in an inclusive and supportive context. (European Commission, 2019)

Essential knowledge, skills and attitudes related to this competence are explained briefly in the following:

- Knowledge - understanding the codes of conduct and rules of communication generally accepted in different societies and environments. It involves knowing one's preferred learning strategies, knowing one's competence development needs and various ways to develop competences and search for the education, training and career opportunities and guidance or support available.

- Skills - include the ability to identify one's capacities, focus, deal with complexity, critically reflect and make decisions. This includes the ability to learn and work both collaboratively and autonomously and to organize and persevere with one's learning, evaluate and share it, seek support when appropriate and effectively manage one's career and social interactions. Individuals should be resilient and able to cope with uncertainty and stress. They should be able to communicate constructively in different environments, collaborate in teams and negotiate. This includes showing 
tolerance, expressing and understanding different viewpoints, as well as the ability to create confidence and feel empathy.

- Attitudes - Building on a positive attitude toward one's personal, social and physical wellbeing and learning throughout one's life. It is based on an attitude of collaboration, assertiveness and integrity. This includes respecting diversity of others and their needs and being prepared both to overcome prejudices and to compromise. Individuals should be able to identify and set goals, motivate themselves, and develop resilience and confidence to pursue and succeed at learning throughout their lives. A problem-solving attitude supports both the learning process and the individual's ability to handle obstacles and change. It includes the desire to apply prior learning and life experiences and the curiosity to look for opportunities to learn and develop in a variety of life contexts. (European Commission, 2019)

\section{Research methodology}

The Republic of Macedonia, as the rest of the European countries, is following the European educational trends regarding the education process and learning in general in times of Covid 19 pandemic. For that matter, efforts are made to secure possibilities of acquiring appropriateeducational opportunities for everyone and to ensure that people obtain knowledge, skills and attitudes which are in line with the society's educational strategy and labor market.

In this research paper the main focus was set on three main components of the personal, social and learning to learning competence:

- component related to the motivation for learning in times of pandemic;

- component of skills, student's perceptions on learning and education in general; and

- competencies of self-regulated learning.

The research was conducted among 120 university students from two different Faculties and four different study programs from University Ss Cyril and Methodius - Skopje. Students represented a heterogenic group from first, third and fourth academic year of study. But they all answered identical electronic questionnaires/polls about their perceptions about education and learning in the academic semester of 2020/2021.

\section{Research results}

First research hypothesis related to students' motivation for learning and education in times of pandemic has been focusing on the student's level of aspiration, i.e., that is their level of motivation for learning, their levels of concentration while learning, their level of focus on certain educational assignment besides actual frustrations and/or confusions. This hypothesis is also focusing on the students' opinions and attitudes towards learning in general as well as its influence in personal and social development.

For the question "In which way do you motivate to learn?", around 65\% (78 students) of the students answered that they are reminding themselves how important is getting a certificate of graduation, than actually learning and internalizing the material. That implies to the current situation where students value certificate qualification more than the actual achieved competencies. 
Students lack of motivation for learning is also noticed in the answers of the question whether learning is fun, where around two thirds of students answered negatively. This is also supported by the answers of the students of the statement l enjoy learning where students actually admit that they do not enjoy the learning process in the current pandemic educational situations, where teaching and learning are electronically based.

Graph 1: Students' opinions of the statement / enjoy learning

\section{I enjoy learning}

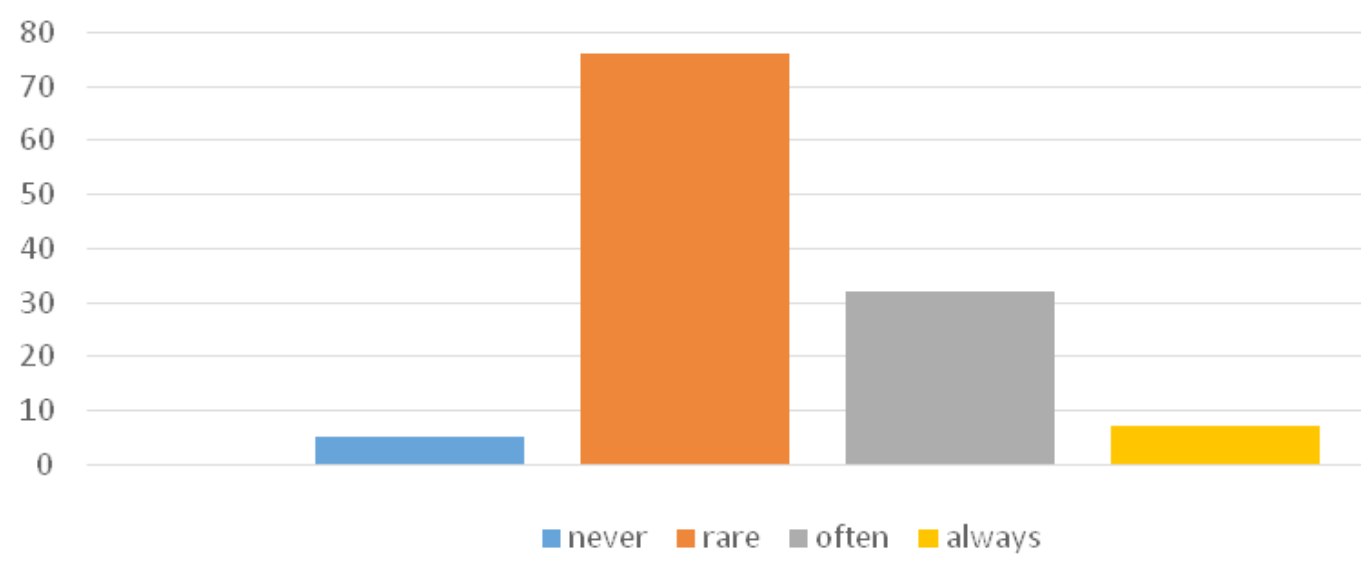

Regarding the second group of questions, related to the students' perceptions on learning and education in general answers were directed towards building a positive attitude on learning, which is a positive indicator for the future development in students' educational and professional area.

For example, in the statement "Learning is important for me and my future", more than two thirds of the questioned students ( 83 students) positively agreed that learning is very much important for them. They also considered learning important for the irfuturewhichimpliesthefacttha tthey are very much aware about the need fo developing the ircompetences in thefuture and be active lifelonglearners.

But, ontheotherhand, students statements point out the dissadvantages, orchallenges that Macedonian educational system faces. To the question related to the ways the students learn the material, $84 \%$ of them answered that most of the time they learn the material by hard. That is a disappointing fact, because the competence "learning how to learn" intercedes for a fulfilled person who has a strong built system of learn how to learn skills and who are capable to manage their own learning and educational path in practice.

Students also agree that the most important objective of learning is acquiring information, which is also related to the fact that memorizing the material (information, facts, etc.) is one of the crucial elements for obtaining a high grade, or passing the exam and it is contradictory with the core idea of the competence "learning how to learn". 
The most important objective of learning is acquiring information

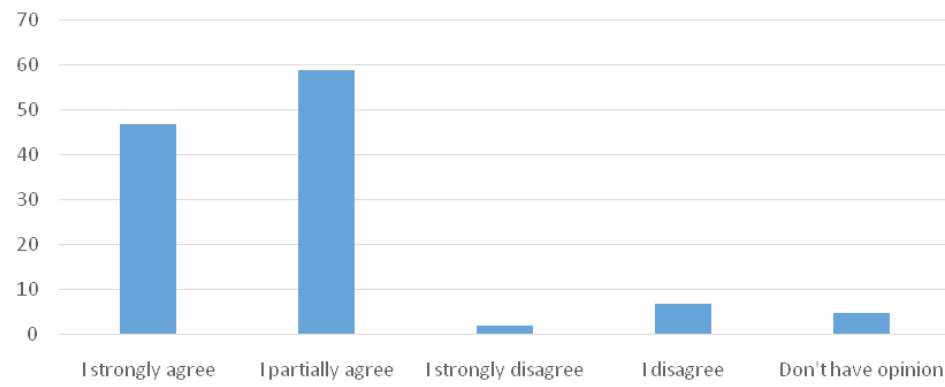

Positive results come from students' perceptions about the statement that lifelong learning is an important educational concept and that they learn outside the university, which implies student's awareness about non-formal and informal learning paths.

The third part of the questionnaire was focused on the students' opinions about their skills and competences to manage their own learning process and career path, that is, we tried to gather data whether students possess certain skills and competencies for selfregulated learning outside formal university education which implies effective use of time, methods and strategies for learning.

Regarding the skills of the interviewed students about their skills for self-regulated learning, or acknowledging their preferred ways of learning and learning methods and techniques, we can conclude that most of the students (around $80 \%$ ) have been underlying the most important parts while learning, which implies that they have been developed certain preferred method of learning. Students also negatively responded to the statement that they use learning sources outside the ones given by the professor (like encyclopedia, on-line searching, libraries, professional books, etc.) which is a problem directly intercorrelated with development of critical thinking and the whole concept of lifelong learning which presupposes learning outside the formal educational system.

Students also stated (73\%) that they don't make schemes, graphs or mind-mapping while learning the academic subjects. They also (64\%) face problems when managing their short-term and long-term learning plans (for example for learning more than one subject in one exam session). This result is due to the fact that students lack of skills for managing their learning process.

I have problems while making short-term and long-term learning plans

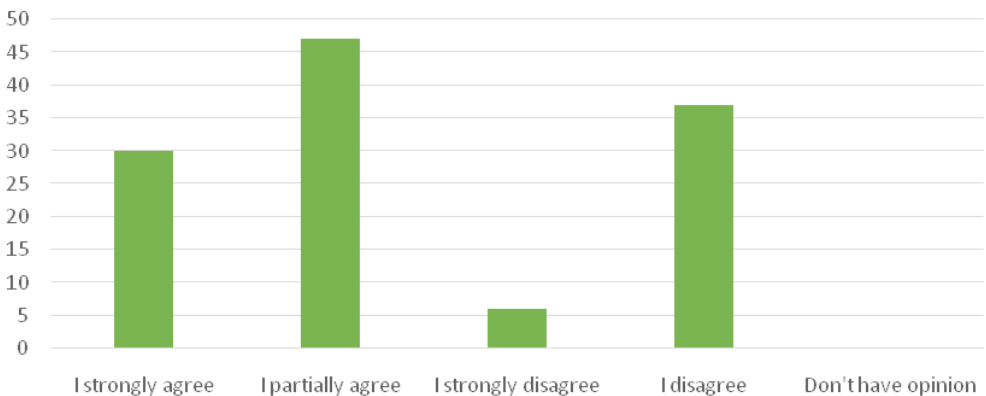


Encouraging results come from inquired students about their answers to the statement that they tend to connect new material with previously learned and internalized knowledge and skills, that can be observed as an small step towards acquiring the competence "learning how to learn".

In the part of the questionnaire about career development, we can conclude that the most of the students ( $90 \%$ of them) at university level obtain self-consciousness about their strong and weak sides of learning, affinities and capability to work and develop and they are aware about in which direction their future career will be developed.

\section{Conclusions and recommendations}

The main results from the gathered data of the conducted research point out to the positive conclusion that student look on learning as one of the crucial preconditions of becoming a fulfilled person and active citizen who can be productive in every area of the societal life, firmly facing and resolving all the challenges that modern society brings on an every-day basis, like the COVID 19 pandemic.

But unfortunately, on the other hand, students are lacking crucial competences and skills which will make their learning process effective and productive. This is a crucial point for reaffirming the competence "learning how to learn" as one of the core competences of the concept of lifelong learning. Gathered results from this research should be one of the priorities for change and reforming the overall educational system by building independent learners who can critically approach challenges in personal and professional life and be active and productive participants in the societies. Lifelong learning as an ideology with all its key competences is a new educational concept that can contribute not only in resolving the issues that humanity faces like poverty, unemployment, illiteracy, etc., but a concept which is contributing towards reinforcing the humanistic aspect of learning and personal fulfilment.

All of the gathered results are just a start from which Macedonian educational policy should start facing the challenges not just in higher education, but in all educational subsystems because of their interconnectedness. Despite the efforts and positive results gained so far, Republic of Macedonia has a lot of work to do in the aspects of:

- Internal and external transformation of the organization of educational system, i.e., reforming the educational process itself in terms of enabling students from all ages to be able to learn how to learn;

- Connecting, affirming and acknowledging the formal, informal and non-formal education as equal parts of one's individual learning path;

- Connecting all educational subsystems with one goal - acknowledging the concept of lifelong learning and making it a reality.

\section{References}

1. CEDEFOP, EURYDICE, (2001), National actions to implement Lifelong Learning in Europe, Brussels: European Commission.

2. Central Council for Education, (1982), The ideals and the Tasks of Lifelong Education: $A$ summary, Tokyo: National Institute for Educational Research of Japan. 
3. Commission of the European Communities (2000), Commission Staff Working Paper: A memorandum on Lifelong Learning, Brussels: Commission of the European Communities.

4. Commission of the European Communities (2005), Recommendation of the European Parliament and of the council on key competences for lifelong learning, London: Commission of the European Communities.

5. Council of the European Union, (2018). Council recommendation on key competences for Lifelong learning, Official Journal of the European Union.

6. Delanty, G. (2002), Challenging knowledge: The university in the knowledge society, Philadelphia: Open University Press.

7. ETF, (2006), A review of international and national developments in the use of qualifications frameworks, Torino: ETF.

8. ETF, (2006), Designing Adult Learning Strategies - the case of South Eastern Europe, Torino: ETF.

9. European Commission, (1995), White Paper of teaching and learning, Brussels: European Council.

10. European Commission, (2002), European report on quality indicators of Lifelong Learning, Brussels: Directorate-General for Education and Culture.

11. European Commission, (2019). Key competences for lifelong learning.Luxembourg: Publications Office of the European Union.

12. EURYDICE, (2000), Lifelong Learning: the contribution of education systems in the Member States of the European Union, Lisbon: EURYDICE.

13. Institute for International Cooperation of the German Adult Education Association, (2006), Adult Education and development: number 67, Bonn: IIZ DVV.

14. Institute for International Cooperation of the German Adult Education Association, (2006), Adult Education and development: number 66, Bonn: IIZ DVV.

15. Jarvis, P. (1995), Adult and Continuing Education Theory and Practice, London: Routledge.

16. Jarvis, P. (2001), The Age of learning: education and the knowledge society, London: Kogan Page.

17. OECD (2005), The definition and selection of key competencies: Executive Summary, bez oznaka: OECD

18. Rizova, E. (2021). Lifelong learning. Skopje: Faculty of philosophy - Skopje.

19. UNESCO, (2021). Embracing a culture of lifelong learning. Hamburg: UIL. 